\title{
Matthieu Liouville, Les Rires de la poésie romantique
}

\section{Wieslaw Mateusz Malinowski}

\section{(2) OpenEdition}

\section{Journals}

\section{Édition électronique}

URL : http://journals.openedition.org/studifrancesi/5982

DOI : 10.4000/studifrancesi.5982

ISSN : 2427-5856

\section{Éditeur}

Rosenberg \& Sellier

\section{Édition imprimée}

Date de publication : 1 mai 2011

Pagination : 179

ISSN : 0039-2944

\section{Référence électronique}

Wieslaw Mateusz Malinowski, «Matthieu Liouville, Les Rires de la poésie romantique », Studi Francesi [En ligne], 163 (LV | I) | 2011, mis en ligne le 30 novembre 2015, consulté le 08 janvier 2021. URL : http://journals.openedition.org/studifrancesi/5982 ; DOI : https://doi.org/10.4000/studifrancesi.5982

Ce document a été généré automatiquement le 8 janvier 2021.

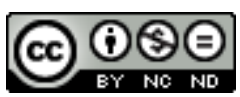

Studi Francesi è distribuita con Licenza Creative Commons Attribuzione - Non commerciale - Non opere derivate 4.0 Internazionale. 


\title{
Matthieu Liouville, Les Rires de la poésie romantique
}

\author{
Wieslaw Mateusz Malinowski
}

\section{RÉFÉRENCE}

MATTHIEU LIOUVILLE, Les Rires de la poésie romantique, Paris, Honoré Champion, 2009

(«Romantisme et Modernités», no 114), pp. 576.

\section{NOTE DE L'AUTEUR}

Erratum: Par erreur d'impression, l'analyse du Journal du Marquis de BomBeLLES, t. VII, 1808-1815, éd. Jeannine Charon-Bordas, Genève, Droz, 2008 (in «Studi francesi», ${ }^{\circ}{ }^{159}$, p. 640) a été attribuée à Eric FRANCALANZA au lieu de Michel ARROus: que ces deux collaborateurs fidèles veuillent bien nous en excuser, et nos lecteurs rectifier le nom véritable du recenseur.

1 En dépit de nombreuses définitions de la poésie excluant l'association du poétique et du comique, le rire n'entre pas, à l'époque romantique, en conflit avec la poésie, il se manifeste au contraire comme une force de renouvellement littéraire: telle est la thèse fondamentale soutenue par l'auteur de l'ouvrage. Quand on sait combien les poètes du romantisme se donnaient pour mission de toucher et d'élever l'âme du lecteur, on se pose là-dessus des questions. Pourtant, la démonstration de Matthieu Liouville est ferme et rigoureuse. Une importante mise au point terminologique prépare le terrain: ironie, grotesque, burlesque, blague, facétie, drôle, bouffon, humeur, humoriste, humour autant de mots dont le champ sémantique se trouve délimité, dès l'Introduction, avec beaucoup de finesse. Sont examinés ensuite, dans la première des quatre grandes parties du travail, les «Rires ludiques». L'auteur s'intéresse ici à l'héritage comique de la poésie, plus particulièrement aux différentes catégories de comique formel et à la poésie de circonstance, à laquelle on associe traditionnellement l'esprit (ce qui 
occasionne une belle réflexion sur l'esprit français et le sentiment de spécificité nationale du rire, pp. 85-92), mais aussi aux relations entre le rire et le sérieux romantique ainsi qu'à la question de l'intertextualité ludique (burlesque, satires et parodies). Il montre, de nombreux exemples à l'appui, que la poésie légère, loin d'être bannie du champ littéraire, acquiert à l'époque romantique un statut nouveau, le rire ludique de la poésie devenant même «une quête et un art poétique» (p. 194).

La deuxième partie du travail est consacrée aux «Rires jaunes et noirs». Des ricanements frénétiques à la satire politique et sociale, en passant par le rictus du sarcasme ou de l'horreur, rire provocateur et agressif, rire qui implique le corps et qui entre en relation avec la mort, c'est à une véritable "guerre des rires» que nous assistons, avec Matthieu Liouville, au sein de la poésie romantique. Les rapports entre «Rire et imagination» sont au centre de la troisième partie de l'ouvrage. À l'aptitude à l'humour se joint en effet au XIX siècle la faculté d'imagination, alliance que résume bien le terme fantaisie; le chercheur voit dans le genre fantastique une source inépuisable de rires. En étudiant les différentes manifestations du rire onirique et les rapports entre l'humour et le fantastique, il constate qu'en fin de compte l'humour se retourne dans la poésie contre l'imagination "pour croître plus sûrement sur sa ruine» (p. 383).

3 Enfin, une sorte de synthèse nous est donnée dans la partie intitulée «Les Métamorphoses de la poésie». Le rire impose sa marque sur toute la poésie qui, sous sa poussée, subit au XIX $x^{e}$ siècle des transformations majeures. Sur le plan esthétique, l'humour provoque et accompagne au sein de la poésie une dispersion énonciative, un éclatement de toutes les instances de l'écriture et des règles de communication, constate l'auteur; à un niveau plus philosophique, il apparaît comme un moyen d'accès au monde des idées: «la figure du bouffon se confond avec celle du sage, le rire et la logique s'entrechoquent pour mieux se mêler», pour former «un mode de transmission et de révélation original» (p. 443). L'étude se termine par une réflexion sur le fonctionnement du rire dans le poème en prose, plus particulièrement sur la nature des relations qui s'instaurent au sein du poétique entre l'humour et la prose. Une vaste bibliographie incite tout lecteur intéressé par la problématique à poursuivre l'enquête.

4 Le grand mérite de Matthieu Liouville est de montrer comment le rire s'intègre naturellement dans l'esthétique romantique, comment il parvient à «réconcilier la poésie tout entière avec la notion, perpétuellement enrichie, de poétique» (p. 515). Livre d'une très grande richesse, à placer parmi les meilleurs ouvrages que nous ayons sur le comique littéraire et les théories du rire. 